\title{
Clinical trials during COVID-19: Keeping clinical trial participants informed during this pandemic
}

\author{
Wong $\mathrm{LX}^{1^{*}}$, Chee $\mathrm{B}^{2}$ and Park JM ${ }^{3}$ \\ ${ }^{1}$ Department of Clinical Research and Leadership, Translational Health Sciences, The George Washington University School of Medicine and Health Sciences, USA \\ ${ }^{2}$ Department of Primary Care, Touro University College of Osteopathic Medicine - California, USA \\ ${ }^{3}$ Department of Medical Education, Rush University Medical College, USA
}

\section{Dear Editor}

Currently, per the World Health Organization (WHO), the novel coronavirus disease 2019 (COVID-19) surpassed five million confirmed cases and the numbers continue to alarmingly climb world-wide [1]. COVID-19 is caused by a severe acute respiratory syndrome coronavirus 2 (SARS-CoV-2) inducing potentially lifethreatening circumstances in all age ranges, primarily in that of 3065 [2]. Especially in light of early studies showing COVID-19 patients with co-morbidities likely to have more severe symptoms and increase risk of death than that of those who did not have co-morbidities $[3,4]$, global municipalities, states and countries have enacted a various forms of quarantine strategies to mitigate the adverse effects of COVID-19 on people and our global society [5].

With ClinicalTrials.gov listing over a third of a million studies active in all 50 American states and 210 countries [6], participants in clinical trials are arguably at increased risks [7], such as financial difficulties, emotional trauma and adverse health outcomes. As with any clinical trial and especially during this pandemic, it is key to maintain deep trust and open communications between the investigator and participant. As a result, the investigator is responsible to continue in preserving a setting that will promote a patient-centric approach to the informed consent process [8], conducting complete disclosure and reassessing voluntariness during COVID-19.

In this setting, in conjunction with collaborative investigators, institutions, ethics review boards and Sponsors, investigators should disclose beyond the traditional elements of the risks, benefits, and alternatives to a clinical intervention [9], such as possible delays in investigational treatments or suspension of clinical trial activities due to COVID-19. This disclosure preserves transparency and underscores how informed consent is not a binding contract that requires participants to commit to a single treatment option. The voluntary process is dynamic and ongoing, which aims to constantly inform the patient about any changes from the start to the end of the clinical trial [10]. Ultimately, it should always be the participant's decision as to whether they would like to continue partaking in the study, provided that they have been presented all their options and undergone the decision-making process.

Hence, despite many competing priorities during COVID-19, I urge investigators to not forget about their participants who have contributed to treatment and cure discovery and put their trust, health and safety into investigators' hands.

\section{Acknowledgments}

We thank the healthcare professionals all around the world combating against COVID-19. Together, we can make a difference to maintain patient safety and improve health outcomes.

Additionally, we thank the following individual for their academic support and guidance in clinical research and the informed consent process: Samar Nasser, PhD MS MPH (The George Washington University) and Andrew H. Ko, MD (University of California, San Francisco).

\section{Financial Disclosure}

Authors have no financial disclosure to report.

\section{Conflict of Interest}

The authors declare that they have no conflict of interest concerning this manuscript.

\section{References}

1. WHO (2020) WHO Coronavirus Disease (COVID-19) Dashboard. World Health Organization.

2. Yi Y, Lagniton PNP, Ye S, Li E, Xu RH (2020) COVID-19: what has been learned and to be learned about the novel coronavirus disease. Int J Biol Sci 16: 1753-1766. [Crossref]

3. Guan WJ, Liang WH, Zhao Y, et al. Comorbidity and its impact on 1590 patients with COVID-19 in China: a nationwide analysis. Eur Respir J 55: 2000547. [Crossref]

4. Wang B, Li R, Lu Z, Huang Y (2020) Does comorbidity increase the risk of patients with COVID-19: evidence from meta-analysis. Aging (Albany NY) 12: 6049-6057. [Crossref]

5. Wilder-Smith A, Freedman DO (2020) Isolation, quarantine, social distancing and community containment: pivotal role for old-style public health measures in the novel coronavirus (2019-nCoV) outbreak. J Travel Med 27: taaa020. [Crossref]

6. https://clinicaltrials.gov/ct2/resources/trends

7. Singh AG, Chaturvedi P (2020) Clinical trials during COVID-19. Head Neck 2: 10. [Crossref]

8. Wong, LX, Bloom, GM, Chee, B (2020) The Complex Maze of the Informed Consen Process: Helping to Improve Comprehension in Clinical Trial Participants with Alzheimer's Disease. JAD Reports 1: 161-164.

${ }^{\star}$ Correspondence to: Louis Wong, MS, Department of Clinical Research and Leadership, Translational Health Sciences, The George Washington University School of Medicine and Health Sciences, USA, E-mail: louiswong415@gwmail. gwu.edu

Received: June 04, 2020; Accepted: June 10, 2020; Published: June 12, 2020 
Wong LX (2020) Clinical trials during COVID-19: Keeping clinical trial participants informed during this pandemic

9. Bal BS, Choma TJ (2012) What to disclose? Revisiting informed consent. Clin Orthop Relat Res 470: 1346-1356. [Crossref]
10. Appelbaum PS, Lidz CW, Klitzman R (2009) Voluntariness of consent to research: a conceptual model. Hastings Cent Rep 39: 30-39. [Crossref]

Copyright: $\odot 2020$ Wong LX. This is an open-access article distributed under the terms of the Creative Commons Attribution License, which permits unrestricted use, distribution, and reproduction in any medium, provided the original author and source are credited. 